Open Access

\title{
Virulence Attenuation of Pectobacterium carotovorum Using N-Acyl-homoserine Lactone Degrading Bacteria Isolated from Potato Rhizosphere
}

\author{
Esmaeil Mahmoudi ${ }^{1 *}$, Badraldin Ebrahim Sayed Tabatabaei ${ }^{2}$ and Vittorio Venturi ${ }^{3}$ \\ ${ }^{1}$ Department of Plant Protection, Khorasgan Branch, Islamic Azad University, Isfahan, Iran \\ ${ }^{2}$ Department of Agricultural Biotechnology, Isfahan University of Technology, Isfahan, Iran \\ ${ }^{3}$ Bacteriology Group, International Center for Genetic Engineering and Biotechnology, Trieste, Italy \\ (Received on January 25, 2011; Revised on July 9, 2011; Accepted on July 24, 2011)
}

\begin{abstract}
Several soil bacteria were found to degrade N-Acylhomoserine lactones (NAHLs), thereby interfering with the bacterial quorum sensing system. In this research, fifteen strains of NAHL degrading rhizobacteria were isolated from potato rhizosphere. Based on phenotypic characteristics and 16S rDNA sequence analyses, the strains were identified as members of genera Bacillus, Streptomyces, Arthrobacter, Pseudomonas and Mesorhizobium. All tested isolates were capable to degrade both synthetic and natural NAHL produced by Pectobacterium carotovorum subsp. carotovorum (Pce) strain EMPCC. In quorum quenching experiments selected isolates, especially Mesorhizobium sp., were markedly reduced the pathogenicity of $\boldsymbol{P c c}$ strain EMPCC in potato tubers and totally suppressed tissue maceration on potato tubers. These led to consider the latter as a useful biocontrol agent against Pectobacterium spp.
\end{abstract}

Keywords: Mesorhizobium, NAHLs, Pectobacterium carotovorum, Quorum sensing

Many bacterial species employ complex communication systems that link cell density and gene expression to regulate a broad range of biological functions (Fuqua et al., 2001; Miller and Bassler, 2001). Such cell-to-cell communication, termed quorum sensing (QS), depends on the production, diffusion, and recognition of small signal molecules. Bacteria recognize the changes in their population density by sensing the concentrations of signal molecules, which are accumulated as bacterial cells proliferate. $\mathrm{N}$ Acyl-homoserine lactones (NAHLs), also known as autoinducers, are widely conserved signal molecules that are present in the quorum-sensing systems of many gramnegative bacteria. Bacteria release, detect, and respond to accumulation of these signal molecules resulting in synchronizing expression of diverse biological functions includ-

\footnotetext{
*Corresponding author.

Phone) +098-03115354002-8, FAX) +098-03115354016

E-mail)e.mahmoudi@khuisf.ac.ir
}

ing bioluminescence, antibiotic synthesis, biofilm formation, swarming, plasmid conjugation, siderophore production and production of virulence determinants (Whitehead et al., 2001). Since pathogenicity or pathogenicity-associated functions are controlled by QS in some major plant and animal pathogens, it has been proposed that the QS system could be an appropriate novel target for biological control agents or drugs in order to attenuate and limit virulence (Faure and Dessaux, 2007). Anti-QS mechanisms have been employed by inhibiting the synthesis or perception of the NAHL signal, as well as its enzymatic degradation by wild-type bacteria and eukaryotes, and genetically modified organisms (Molina et al., 2003; Rasmussen and Givskov, 2006).

The NAHL-degrading enzymatic activities were initially discovered in a few bacterial species (Dong et al., 2000; Leadbetter and Greenberg, 2000). However, they have now been reported in Proteobacteria belonging to the Agrobacterium, Bosea, Commamonas, Delftia, Ochrobactrum, Pseudomonas, Ralstonia, Sphingopyxis and Variovorax genera (d'Angelo-Picard et al., 2005; Flagan et al., 2003; Huang et al., 2003; Jafra et al., 2006; Leadbetter and Greenberg, 2000; Lin et al., 2003; Park et al., 2003; Uroz et al., 2003). In addition degrading activities have been originally reported in Actinobacteria and Firmicutes, such as Arthrobacter, Bacillus, Rhodococcus and Streptomyces (Dong et al., 2000; Lee et al., 2002; Park et al., 2005; Uroz et al., 2003). These NAHL-degrading bacteria were recovered from different environments such as soil, rhizosphere and abiotic biofilm.

The aims of this study were: (i) to isolate and identify bacteria that degrade NAHL molecules; (ii) to evaluate their NAHL degradation pattern; and (iii) to evaluate the efficacy of microbial-based NAHL degradation for biological control of the pathogen $P$. carotovorum subsp. carotovorum on potato plant. 


\section{Material and Methods}

Bacterial strains, media and culture conditions. Bacterial strains were isolated from the rhizosphere of potato plants collected from different potato growing areas in Iran. Pectobacterium carotovorum subsp. carotovorum strain EMPCC (Laboratory of Plant Pathology, IAU- Science and Research Branch, Tehran, Iran) was used as soft rot pathogen and source of naturally produced NAHL molecules. Escherichia coli SM88, a derivative of E. coli DH5 $\alpha$ harboring the pME6863 plasmid (Reimmann et al., 2002) (provided by Vittorio Venturi, ICGEB, Area Science park, Italy) was used as positive control for NAHL degradation agent in experiments. Chromobacterium violaceum CV026 (McClean et al., 1997) (provided by Vittorio Venturi, ICGEB, Area Science park, Italy) and Agrobacterium tumefaciens NT1 (Shaw et al., 1997) (provided by Yves Dessaux, CNRS, Gif-sur-Yvette, France) were used as the indicator strains for AHLs detection. The media used were Luria-Bertani (LB), King's-B (KB) (Schaad et al., 2001) and $\mathrm{AB}$ minimal medium that was supplemented when required with $2 \%$ mannitol (Chilton et al., 1974) or with cycloheximide $(50 \mu \mathrm{g} / \mathrm{l})$. For growth of $E$. coli SM88, the media was supplemented with tetracycline $(10 \mathrm{mg} / \mathrm{l})$. All bacteria were grown at $27^{\circ} \mathrm{C}$, except for biosensors and E. coli SM88, which were grown at $28^{\circ} \mathrm{C}$ and $37^{\circ} \mathrm{C}$, respectively. All NAHLs standard used in this study were purchased from Sigma (Sigma-Aldrich, Inc., St. Louis, Mo., USA).

Isolation of Bacterial strains. Soil and potato root samples were collected from commercial potato fields located in Isfahan province, Iran. The original suspensions were made by adding 1 gram of either samples in $10 \mathrm{ml}$ sterile distilled water. Serial dilutions are prepared in $10 \mathrm{ml}$ of sterile $0.8 \%$ $\mathrm{NaCl}$ and a loopful of the most diluted suspensions were spread on King's medium B and LB medium (1\% tryptone, $0.5 \%$ yeast extract and $0.5 \% \mathrm{NaCl}$ ) containing $50 \mathrm{mg} / \mathrm{mL}$ cycloheximide. Plates were incubated in the dark at $27^{\circ} \mathrm{C}$ for $72 \mathrm{~h}$. The bacterial colonies with different morphologies were randomly picked from both media and the purified cultures were stored in glycerol medium at $-80^{\circ} \mathrm{C}$.

Screening of bacterial isolates for NAHL degradation activity. Screening for AHL degrading activities of potato bacterial isolates was performed as described by Morohoshi et al., 2009. Because NAHLs are sensitive to alkaline $\mathrm{pH}$ (Yates et al., 2002), all degradation assays were done in AB and LB media at $\mathrm{pH}$ 6.5. The $\mathrm{N}$-hexanoyl homoserine lactone (C6-HSL) was used as first target molecule in this degradation assay. Bacterial strains were incubated into 5 $\mathrm{ml}$ LB medium containing $5 \mathrm{mg} / 1 \mathrm{C} 6-\mathrm{HSL}$ on rotary shaker for $24 \mathrm{~h}$ at $27^{\circ} \mathrm{C}$. Cells were removed by centrifuge at $2000 \times \mathrm{g}$ for $5 \mathrm{~min}$. the culture supernatant $(50 \mu \mathrm{l})$ was transferred into the wells of a 96-well plate. The full-grown culture of the CV026 biosensor was diluted 1:100 in fresh LB medium, and $500 \mu \mathrm{l}$ of the diluted culture were inoculated into each well. A control experiment involving non-inoculated degradation medium processed as for the inoculated media was performed at the same time as the degradation assays. E. coli SM88 was used as positive NAHL degrading bacterium. After incubation for $24 \mathrm{~h}$ at $30{ }^{\circ} \mathrm{C}$ on rotary shaker, the remaining C6-HSL was detected through violacein production by the $C$. violaceum reporter strain. To determine the NAHL degradation pattern of selected isolates, individual stock colonies were inoculated in $5 \mathrm{ml} \mathrm{LB}$ medium supplemented each with one of NAHLs standard with following concentrations: $6 \mathrm{mg} / \mathrm{l}$ (C8-HSL); $6.5 \mathrm{mg} / 1$ (C12-HSL) and $6.5 \mathrm{mg} / 1$ (C14-HSL). Cultures were incubated at $27^{\circ} \mathrm{C}$ for $24 \mathrm{~h}$ on rotary shaker. The control experiment with non-inoculated degradation medium was performed to assess degradation assays. Following this, bacterial cells were removed by centrifugation at $2,000 \times \mathrm{g}$ for $5 \mathrm{~min}$ and assay was performed as described above except for long chain NAHL, that NTI strain was used as biosensor.

NAHL production by $P$.c. subsp. carotovorum EMPCC. P.c. subsp. carotovorum EMPCC was streaked as homogeneous line on LB medium and biosensor strain, $C$. violaceum CV026, was spotted at a distance of 6-7 mm from the EMPCC line. After incubation at $28^{\circ} \mathrm{C}$ for $24 \mathrm{~h}$, appearance of violet pigment in CV026 colony revealed the production of violacein by $\mathrm{CV} 026$ as well as production of NAHL by EMPCC.

Degradation ability of natural NAHL produced by $P$.c. subsp. carotovorum EMPCC. P.c. subsp. carotovorum strain EMPCC was inoculated in $5 \mathrm{ml} \mathrm{LB}$ medium at $27^{\circ} \mathrm{C}$ by shaking for $24 \mathrm{~h}$. The bacterial suspension was centrifuged at $2,000 \times \mathrm{g}$ for $5 \mathrm{~min}$. Culture supernatant was extracted twice adding an equal volume of ethyl acetate. The residue was added with fresh LB medium and all test strains (Table 1) were inoculated in this combined medium. Bacterial cultures were incubated at $27^{\circ} \mathrm{C}$ for $20 \mathrm{~h}$ (for SM88 at $37^{\circ} \mathrm{C}$ ) and NAHL residue was detected as described by Shaw et al. (1997).

Identification of the selected isolates. To confirm preliminary identification of bacterial isolates determined by some phenotypic characteristics (Schaad et al., 2001), the selective strains were subjected to PCR analysis. The DNA coding regions for the $16 \mathrm{~S}$ rRNA of each isolate were amplified by PCR using the universal primers pA (5'- 
Table 1. Properties of NAHL degrading bacteria isolate from potato rhizosphere

\begin{tabular}{|c|c|c|c|c|c|c|c|c|c|}
\hline \multirow[b]{2}{*}{ Strains } & \multirow{2}{*}{$\begin{array}{l}\text { rrs sequencing } \\
\text { identification }\end{array}$} & \multirow{2}{*}{$\begin{array}{l}\text { GenBank } \\
\text { Acc. no. }\end{array}$} & \multirow[b]{2}{*}{ Gram } & \multirow[b]{2}{*}{ Colony and cell morphology } & \multicolumn{5}{|c|}{ "Degradation ability ${ }^{\mathrm{b}}$} \\
\hline & & & & & $\begin{array}{l}\text { C6- } \\
\text { HSL }\end{array}$ & $\begin{array}{l}\text { C8- } \\
\text { HSL }\end{array}$ & $\begin{array}{l}\text { C12- } \\
\text { HSL }\end{array}$ & $\begin{array}{l}\text { C14- } \\
\text { HSL }\end{array}$ & $\begin{array}{l}\text { EMPCC } \\
\text { NAHL }^{c}\end{array}$ \\
\hline$\overline{\text { S6 }}$ & Bacillus sp. & EU977693.1 & + & White, rod shape, motile & ++ & ++ & ++ & ++ & ++ \\
\hline S22 & Bacillus sp. & HМ748447.1 & + & White, rod shape, motile & ++ & ++ & ++ & ++ & ++ \\
\hline S27 & Bacillus sp. & HM776218.1 & + & White, rod shape, motile & ++ & ++ & ++ & ++ & ++ \\
\hline AM35 & Bacillus sp. & HМ748447.1 & + & White, rod shape, motile & ++ & ++ & ++ & ++ & ++ \\
\hline AM38 & Bacillus sp. & EU240440.1 & + & White, rod shape, motile & ++ & ++ & ++ & ++ & ++ \\
\hline EA60 & Bacillus sp. & FJ866758.1 & + & White, rod shape, motile & ++ & ++ & ++ & ++ & ++ \\
\hline EA73 & Bacillus sp. & AY948211.1 & + & White, rod shape, motile & ++ & ++ & ++ & ++ & ++ \\
\hline EA85 & Bacillus sp. & D26185.1 & + & White, rod shape, motile & ++ & ++ & ++ & ++ & ++ \\
\hline DMS133 & Bacillus sp. & HM188452.1 & + & White, rod shape, motile & ++ & ++ & ++ & ++ & ++ \\
\hline S5 & Mesorhizobium & AF410896.1 & - & White, rod shape, motile & ++ & ++ & ++ & ++ & ++ \\
\hline EA113 & Streptomyces sp. & HM748050.1 & + & White, like filamentous, non-motile & + & + & ++ & ++ & + \\
\hline AM51 & Arthrobacter sp. & AY444858.1 & + & White to grayish, rod, non-motile & ++ & ++ & + & + & ++ \\
\hline AM43 & Arthrobacter sp. & AY731366.1 & + & White to grayish, rod, non-motile & ++ & ++ & + & + & ++ \\
\hline S15 & Arthrobacter sp. & AY635865.1 & + & White to grayish, rod, non-motile & ++ & ++ & + & + & ++ \\
\hline EA101 & Pseudomonas sp. & AJ969084.1 & - & $\begin{array}{l}\text { White, rod, fluorescent on King-B, } \\
\text { motile }\end{array}$ & ++ & ++ & + & + & + \\
\hline SM88 & E. coli & - & - & White, rod shape, motile & ++ & ++ & ++ & ++ & ++ \\
\hline
\end{tabular}

a: BLAST homology searches (GenBank Acc. no.)

b: NAHL degrading ability was performed as described in methods.

c: P.c. subsp. carotovorum strain EMPCC used as NAHL production source, + : low degrading ability, ++ : high degrading ability

AGAGTTTGATCCTGGCTCAG) and pH (5'-AGGAGGTGATCCAGCCGCA), which allowed the amplification of almost the entire gene (Bruce et al., 1992). DNA extraction for strains was performed as described previously by Manzano et al. (2003). Polymerase chain reactions were performed in a total reaction volume of $50 \mu$ containing $1 \mathrm{X}$ PCR buffer, $100 \mu \mathrm{M}$ of each dNTP, $1.5 \mathrm{mM} \mathrm{MgCl}_{2}, 0.1 \mu \mathrm{M}$ primers, 100 ng of DNA extract and $1 \mathrm{U}$ of Taq DNA Polymerase (Cinagene, IRIB). The following temperature cycle was used: an initial denaturation step of $5 \mathrm{~min}$ at $95^{\circ} \mathrm{C}$ followed by 30 cycles of $1 \mathrm{~min}$ denaturation at $95^{\circ} \mathrm{C}, 1 \mathrm{~min}$ annealing at $56^{\circ} \mathrm{C}$ and $1 \mathrm{~min} 30 \mathrm{~s}$ extension at $72^{\circ} \mathrm{C}$ and a final extension step of $5 \mathrm{~min}$ at $72^{\circ} \mathrm{C}$. The amplification yielded a product of ca. $1500 \mathrm{bp}$, which was analyzed by electrophoresis on $0.8 \%$ agarose gel and then by staining with ethidium bromide (Sambrook et al., 2001). The resulting PCR products were sequenced by an BigDye Terminator and ABI Prism 3700 Genetic Analyzer (Macrogene, World Meridian Venture Center, Korea), and at least 400 bp were subjected to the BLAST analysis within the NCBI database. Some sequence comparisons authorized identification of isolates at the species level and for others the only genus level was retained for homogeneity.

Ability of the tested strains to attenuate potato tissue maceration by $P$. carotovorum subsp. carotovorum. The assay was performed on potato tubers (cv. Agria) as described by Lojkowska et al. (1995). Potato tubers were washed and surface sterilized by two consecutive incubations with sodium hypochlorite ( $1 \%$ chlorine deg.), extensively rinsed with sterile water. The tubers were dried under sterile conditions and then were sprayed with $70 \%$ ethanol. They were dried again and were kept for co-inoculation method. Strains used in this assay were $P$. carotovorum subsp. carotovorum EMPCC (as pathogen) and AM51, S5 and DMS133 as biocontrol agents (quenchers). Strains were cultivated overnight at $27^{\circ} \mathrm{C}$ in LB medium, suspended and diluted in sterile $0.8 \% \mathrm{NaCl}$. Each tuber was inoculated with $20 \mu \mathrm{l}$ of bacterial suspension including pathogen, pathogen with the quencher and quencher alone. Four potato tubers were used for each combination of strains. The experiments were repeated twice. After inoculation, the potato tubers were incubated in a moisture chamber (over $90 \%$ humidity) at $25^{\circ} \mathrm{C}$. Three days after infection, the tubers were cut in the middle and the results were assessed by visual inspection and photographed.

\section{Results}

Isolation and Screening of degrading NAHLs bacteria. Among forty-five rhizospheric soils and root samples, eighty-four individual colonies with different morphologies 


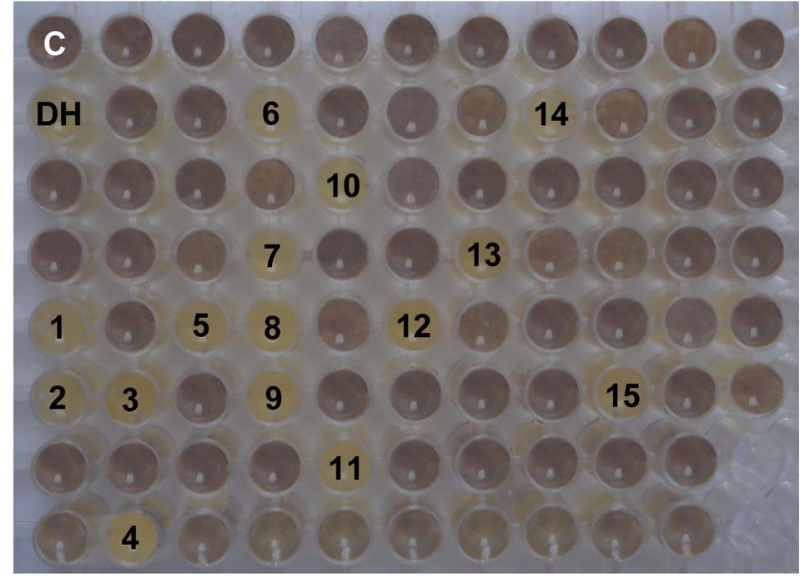

Fig. 1. Detection of NAHL-degrading isolates. The NAHLdegrading isolates were detected by inhibition of synthesis of violacein by $C$. violaceum $\mathrm{CV} 026$ in the presence of C6-HSL at 6 $\mathrm{mg} / \mathrm{l}$. The fifteen NAHL-degrading isolates are numbered from 1 to 15 . C (control) degradation assay performed without bacteria. The DH is E. coli DH5a (SM88) carrying aiiA lactonase encoding gene was used as positive NAHL degrading bacterium. Numbers 1 to 15 encoded as S5, S6, S15, S22, S27, AM35, AM38, AM43, AM51, EA60, EA73, EA85, EA101, EA113 and DMS133, respectively. The picture was taken after $24 \mathrm{~h}$ incubation.

were screened for NAHL degradation. Application of the pigment induction-based indicators, Chromobacterium violaceum CV026 and Agrobacterium tumefasciens NT1 for short chain and long chain carbon NAHLs respectively, allowed us to screen feasibly all NAHL degraders as described by McClean et al., 1997; Shaw et al., 1997. The results revealed that fifteen isolates completely degraded 5 $\mathrm{mg} / \mathrm{l}$ of C6-HSL after $24 \mathrm{~h}$ and violacein induction was inhibited in the CV026 biosensor (Fig. 1). In order to characterize NAHL degradation patterns of the selected isolates, four synthesized unsubstituted NAHL and crude cell culture extract of $P$. carotovorum subsp. carotovorum strain EMPCC as natural NAHL were used. Results revealed that all tested strains degrade all NAHLs types under same conditions with high or low degradation activity (Table 1). In fact, the degradation properties of the various strains differed with respect to their substrate preferences. For instance, strains S6, S22, S27 and AM35 completely degraded all NAHLs as well as culture extract of EMPCC after $24 \mathrm{~h}$ (Fig. 2). These isolates were identified as Bacillus spp., which are known to have high NAHL degrading activity (Dong et al., 2000 and 2002). The other four strains namely AM51, AM43, S15 and EA101 could hardly degrade $5 \mathrm{mg} / \mathrm{l} \mathrm{C6}$ and C8-HSL after $24 \mathrm{~h}$.

Therefore, reminiscent of $\mathrm{C} 12$ and C14-HSLs in cell culture supernatant and in turn, weak blue pigment production by NT1 biosensor, revealed their inability to degrade $6 \mathrm{mg} / \mathrm{l}$ of long chain NAHLs completely. Despite complete degradation of long chain NAHLs (C12 and C14HSL) by Streptomyces sp. EA113, a trace of violacein production was induced when CV026 cultured on supernatant of $\mathrm{C} 6$ and C8-HSL medium. In addition, all tested strains excluding EA101 and EA113, completely degraded natural NAHL produced by $P$. carotovorum subsp. carotovorum EMPCC (Fig. 3, Table 1). The results described above indicated that all tested isolates were able to degrade various NAHLs with different abilities.

Identification of the NAHL degrading isolates. Bacterial
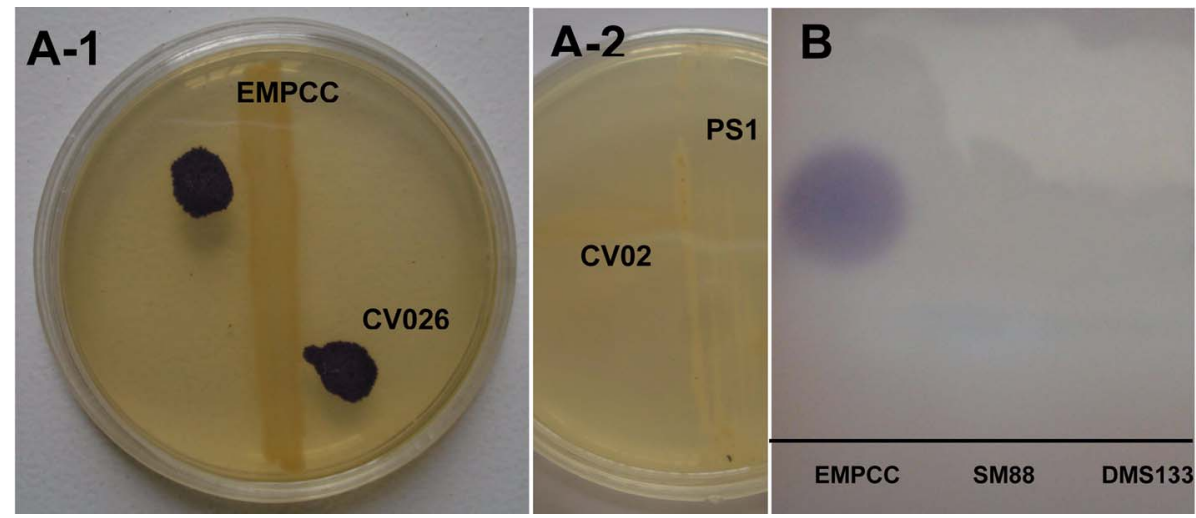

Fig. 2. (A-1) NAHL production by P. carotovorum subsp. carotovorum strain EMPCC. Test strain was streaked as a homogeneous line on LB medium and biosensor strain, $C$. violaceum CV026, was spotted at $10 \mathrm{~mm}$ from the test strain. Development of violet pigment in CV026 colonies revealed the production of violacein by CV026 as well as production of NAHL by EMPCC. (A-2) Pseudomonas fluorescens strain PS1 was used as non-NAHL producing control. (B) Thin layer chromatogram for degradation of NAHL produced by P.c. subsp. carotovorum strain EMPCC. Test strain was inoculated into LB medium and after $24 \mathrm{~h}$ incubation at $27^{\circ} \mathrm{C}$, free cell culture supernatant was extracted with ethyl acetate. The extract was added into fresh LB medium and selected strains (DME133 and SM88) were cultured in it. After $24 \mathrm{~h}$, culture supernatant was extracted with ethyl acetate and NAHL disappearance was revealed using the biosensor strain Chromobacterium violaceum CV026 as described in methods. 


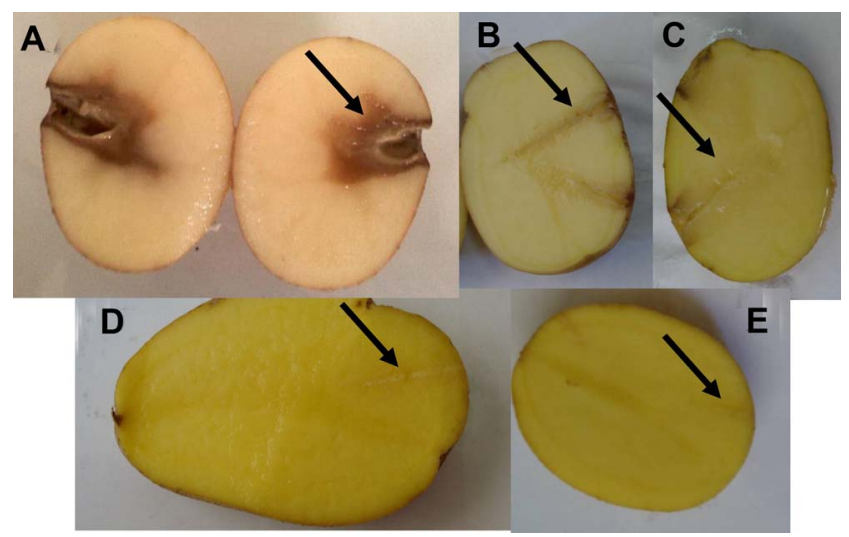

Fig. 3. Attenuation of the maceration capacity of Pectobacterium carotovorum subsp. carotovorum strain EMPCC by selected rhizobacteria. A: Inoculation of $20 \mathrm{ml}$ of EMPCC alone at about $10^{6} \mathrm{cfu}$ per tuber; B, C and D: co-inoculation of EMPCC at about $10^{6}$ cfu per tuber with selected isolates AM51 (Arthrobacter sp.), S5 (Mesorhizobium sp.) and DMS133 (Bacillus sp.). E: A negative control consisting of a tuber treated with $0.8 \% \mathrm{NaCl}$.

16S rRNA genes of all putative bacterial NAHLs degraders were amplified by PCR using $\mathrm{pA}$ and $\mathrm{pH}$ primers as described above. DNA sequences were compared to those found in the data banks using the online FASTA search engine (http://www.ncbi.nlm.nih.gov). All the 16S rDNA gene sequences exhibited similarity between $85-100 \%$ with described genera. This is supported by preliminary identification of the isolates. Blast analysis indicated that nine of the isolates i.e. S6, S22, S27, AM35, AM38, EA60, EA73, EA85 and DMS133 belonged to Bacillus species. Within $B$. cereus group, the $B$. anthracis, $B$. cereus and $B$. thuringiensis were shown NAHL degrading activity with possible presence of NAHL-degrading aiiA gene (Dong et al., 2000). In this study, we isolated two strains of $B$. subtilis as NAHL degrading Bacillus species. B. subtilis have not been reported as an NAHL degrading species and does not belong to the $B$. cereus group. Isolate $\mathrm{S} 5$ showed $90 \%$ similarity to Mesorhizobium species, has been found to degrade various NAHLs. The latter was already confirmed by Funami et al. (2005) to be able to degrade NAHLs. The two other identified genera with NAHL degrading activities were Arthrobacter (strains AM43, AM51 and S15) and one Streptomyces strain encoded as EA113 which already described as capable of NAHL degradation with long chain degradation preference (Park et al., 2005).

Biocontrol of P. carotovorum subsp. carotovorum EMPCC by NAHL degrading bacteria. The biocontrol activity of tested isolates (Table 1) was performed against $P$. carotovorum subsp. carotovorum EMPCC, with this knowledge that its virulence is regulated by QS with 3-oxo-C6HSL as an essential signal (Dong et al., 2002). As shown in Fig. 3, the direct inoculation of $P$. carotovorum subsp. carotovorum EMPCC caused extensive tissue maceration in $48 \mathrm{~h}$ incubation time. Whereas co-inoculation of EMPCC with NAHL degrading bacteria led to substantial reduction in tissue maceration compared to the pathogen alone (Fig. 3). In this regard, the inhibition activity of the B. subtilis strain DMS133 was more pronounced than other tested isolates. In contrast, the ability of EMPCC to macerate potato tubers tissue was attenuated by Atrhrobacter sp. AM51 and significantly reduced by Mesorhizobium sp. S5 when coinoculated with EMPCC at $10^{6} \mathrm{cfu} / \mathrm{ml}$ (Fig. 3).

\section{Discussion}

The biological degradation of quorum sensing signal molecules is an important way in interrupting expression of regulated by quorum-sensing. In screening for NAHL degrading bacteria it was found that major soil and potato root surface bacteria which are taxonomically diverse are able to degrade NAHLs signal molecules. According to previous results (Dong et al., 2000; Angelo-Picard et al., 2004 and Jafra et al., 2006), 10-20\% of total cultivable bacteria in soil are able to degrade NAHLs. This study allowed the isolation of several NAHL degrading strains from potato rhizosphere; $15 / 84$ isolates were identified as Mesorhizobium, Pseudomonas, Bacillus, Streptomyces, and Arthrobacter. The most potent degrading NAHL strains were found among Bacillus spp. with about $60 \%$ isolation frequency, while four other genera were isolated at much lower frequencies (Arthrobacter 20\%; Streptomyces 7\%; Mesorhizobium 7\% and Pseudomonas 6\%).

Previews studies by Dong et al. (2000), Molina et al. (2003) and Park et al. (2003, 2005) revealed that Bacillus, Pseudomonas, Arthrobacter and Streptomyces isolates possess NAHL degrading properties. However, just one report was found to explain this trait in Mesorhizobium (Funami et al., 2005). All NAHL degrading isolates completely degrade NAHL in crude culture extract of EMPCC. 3-Oxo-C6HSL is signal molecule produced by $P$. carotovorum, which regulates production of virulence determinants such as extracellular enzymes was interrupted in standard quorum quenching experiments.

To set up quenching experiments we used Bacillus sp. strain DMS133, Artherobacter sp. strain AM51 and Mesorhizobium strain S5 as interfering agents, since during degradation assays these were demonstrated to be the most efficient NAHL-degrading activities. In quenching experiments, all tested isolates especially Bacillus sp. DMS133 inhibited pathogen growth rates and effectively reduced plant tissue maceration (Fig. 3). A possible approach in developing modern disease management is to target the QS 
regulation system which controls the expression of major pathogenicity determinants (Dong et al., 2007; Sperandio, 2007). NAHL degrading rhizobacteria in this respect could potentially be then used for biological control NAHL producing plant pathogenic bacteria. Any success in their application will depend on population densities of the antagonists and the efficiency with which the NAHLs are inactivated (Jafra et al., 2006). Characterization of NAHL degrading bacteria from different sources, particularly from rhizosphere, will be helpful in identifying potential bacteria to be used as biocontrol agents. Dong et al. (2002), Molina et al. (2003), Jafra et al. (2006) and Morohoshi et al. (2009) reported a possibility for attenuating the virulence of $P$. carotovorum on potato introducing of quorum sensing interfering bacteria. These studies, as well as the data presented in this report, further support the promising strategy for the biocontrol and prevention of $P$. carotovorum infections through NAHL signal degradation.

\section{Acknowledgment}

This work was supported by a grant from the Khorasgan Branch-Islamic Azad University, Iran (research project no. 411-1390/4/24). The Authors thank Dr. Nader Hasanzadeh for critical reading the manuscript.

\section{References}

Angelo-Picard, C., Faure, D., Carlier, A., Uroz, S., Raffoux, A., Fray, R. and Dessaux, Y. 2004. Dynamics of bacterial populations in the rhizosphere of tobacco plants producing - or not the quorum sensing signals hexanoyl- and 3-oxohexanoylhomoserine lactone. FEMS Microbiol. Ecol. 51:19-29.

Angelo-Picard, C., Faure, D., Penot, I. and Dessaux, Y. 2005. Diversity of $\mathrm{N}$-acyl homoserine lactone-producing and degrading bacteria in soil and tobacco rhizosphere. Environ. Microbiol. 7:1796-1808.

Bruce, K. D., Hiorns, W. D., Hobman, J. L., Osborn, A. M., Strike, P. and Ritchie, D. A. 1992. Amplification of DNA from native populations of soil bacteria by using the polymerase chain reaction. Appl. Environ. Microbiol. 58:3413-3416.

Chilton, M., Currier, T. C., Farrand, S. K., Bendich, A. J., Gordon, M. P. and Nester, E. W. 1974. Agrobacterium tumefaciens DNA and PS8 bacteriophage DNA not detected in crown gall tumors. Proc. Natl. Acad. Sci. USA 71:3672-3676.

Dong, Y. H., Wang, L. Y. and Zhang, L. H. 2007. Quorumquenching microbial infections: mechanisms and implications. Philos. Trans. R. Soc. Lond. B Biol. Sci. 362:1201-1211.

Dong, Y. H., Gusti, A. R., Zhang, Q., Xu, J. L. and Zhang, L. H. 2002. Identification of quorum-quenching $\mathrm{N}$-acyl homoserine lactonases from Bacillus species. Appl. Environ. Microbiol. 68:1754-1759.

Dong, Y. H., Xu, J. L., Li, X. Z. and Zhang, L. H. 2000. AiiA, an enzyme that inactivates the acylhomoserine lactone quorumsensing signal and attenuates the virulence of Erwinia carotovora. Proc. Natl. Acad. Sci. 97:3526-3531.

Faure, D. and Dessaux, Y. 2007. Novel biocontrol strategies directed at Pectobacterium carotovorum. Eur. J. Plant Pathol. 119:353-365.

Flagan, S., Ching, W. K. and Leadbetter, J. R. 2003. Arthrobacter strain VAI-A utilizes acyl-homoserine lactone inactivation products and stimulates quorum signal biodegradation by Variovorax paradoxus. Appl. Environ. Microbiol. 69:909-916.

Funami, J., Yoshikane, Y., Kobayashi, H., Yokochi, N., Yuan, B., Iwasaki, K., Ohnishi, K. and Yagi, T. 2005. 4-Pyridoxolactonase from a symbiotic nitrogen-fixing bacterium Mesorhizobium loti: Cloning, expression, and characterization. Bioch. Biophysic. Act. 1753:234-239.

Fuqua, W. C., Winans, S. C. and Greenberg, E. P. 1994. Quorum sensing in bacteria: The LuxR/LuxI family of cell densityresponsive transcriptional regulators. J. Bacteriol. 176:269275.

Huang, J. J., Han, J. I., Zhang, L. H. and Leadbetter, J. R. 2003. Utilization of acyl-homoserine lactone quorum signals for growth by a soil Pseudomonad and Pseudomonas aeruginosa PAO1. Appl. Environ. Microbiol. 69:5941-5949.

Jafra, S., Przysowa, J., Czajkowski, R., Michta, A., Garbeva, P. and Vander Wolf, J. M. 2006. Detection and characterization of bacteria from the potato rhizosphere degrading $\mathrm{N}$-acylhomoserine lactone. Can. J. Microbiol. 52:1006-1015.

Leadbetter, J. R. and Greenberg, E. P. 2000. Metabolism of acylhomoserine lactone quorum-sensing signals by Variovorax paradoxus. J. Bacteriol. 182:6921-6926.

Lee, S. J., Park, S. Y., Lee, J. J., Yum, D. Y., Koo, B. T. and Lee, J. K. 2002. Genes encoding the $\mathrm{N}$-acyl homoserine lactone degrading enzyme are widespread in many subspecies of Bacillus thuringiensis. Appl. Environ. Microbiol. 68:39193924.

Lin, Y. H., Xu, J. L., Hu, J., Wang, L. H., Ong, S. L., Leadbetter, J. R. and Zhang, L. H. 2003. Acyl-homoserine lactone acylase from Ralstonia strain XJ12B represents a novel and potent class of quorum-quenching enzymes. Mol. Microbiol. 47: 849-860.

Lojkowska, E., Masclaux, C., Boccara, M., Robert-Baudouy, J. and Cotte-Pattat, H. N. 1995. Characterization of the pell gene encoding a novel pectate lyase of Erwinia chrysanthemi 3937. Mol. Microbiol. 16:1183-1195.

Manzano, M., Cocolin, L., Cantoni, C. and Comi, G. 2003. Bacillus cereus, Bacillus thuringiensis and Bacillus mycoides differentiation using a PCR-RE technique. Int. J. Food Microbiol. 81:249-254.

McClean, K. H., Winson, M. K., Fish, L., Taylor, A., Chhabra, S. R., Camara, M., Dayykin, M., Lamb, J. H., Swift, S., Bycroft, B. W., Stewart, G. S. A. B. and Williams, P. 1997. Quorum sensing and Chromobacterium violaceum: exploitation of violacein production and inhibition for the detection of $\mathrm{N}$-acyl homoserine lactones. Microbiology 143:3703-3711.

Miller, M. B. and Bassler, B. L. 2001. Quorum sensing in bacteria. Annu. Rev. Microbiol. 55:165-199. 
Molina, L., Constantinescu, F., Michel, L., Reimmann, C., Duffy, B. and Défago, G. 2003. Degradation of pathogen quorumsensing molecules by soil bacteria: a preventive and curative biological control mechanism. FEMS Microbiol. Ecol. 1522: $1-11$.

Morohoshi, T., Someya N. and Ikeda, T. 2009. Novel N-Acylhomoserin lactone- degrading bacteria isolate from the leaf surface of Solanum tuberosum and their quorum quenching properties. Biosci. Biotechnol. Biochem. 73:2124-2127.

Park, S. Y., Kang, H. O., Jang, H. S., Lee, J. K., Koo, B. T. and Yum, D. Y. 2005. Identification of extracellular N-acylhomoserine lactone acylase from a Streptomyces sp. and its application to quorum quenching. Appl. Environ. Microbiol. 71:2632-2641.

Park, S. Y., Lee, S. J., Oh, T. K., Oh, J. W., Koo, B. T., Yum, D. Y., and Lee, J. K. 2003. AhlD, an N-acylhomoserine lactonase in Arthrobacter sp. and predicted homologues in other bacteria. Microbiology 149:1541-1550.

Rasmussen, T. B. and Givskov, M. 2006. Quorum sensing inhibitors: a bargain of effects. Microbiology 152:895-904.

Reimmann, C., Ginet, N., Michel, L., Keel, C., Michaux, P., Krishnapillai, V., Zala, M., Heurlier, k., Triandafillu, K., Harms, H., Defago, G. and Hass, D. 2002. Genetically programmed autoinducer destruction reduces virulence gene expression and swarming motility in Pseudomonas aeruginosa PAO1. Microbiology 148:923-932.

Sambrook, J., Fritsch, E. F. and Maniatis, T. 2001. Molecular Cloning: A Laboratory Manual. Cold Spring Harbor Labora- tory Press, Cold Spring Harbor, NY, USA. 476 pp.

Schaad, N. W., Jones, J. B. and Chun, W. 2001. Laboratory Guide for Identification of plant pathogenic bacteria. APS Press. St. Paul., Minnesota, USA. 373 pp.

Shaw, P. D., Ping, G., Daly, S. L., Cha, C., Cronan, J. E., Jr, Rinehart, K. L. and Farrand, S. K. 1997. Detecting and characterizing $\mathrm{N}$-acyl-homoserine lactone signal molecules by thin layer chromatography. Biochem. J. 94:6036-6041.

Sperandio, V. 2007. Novel approaches to bacterial infection therapy by interfering with bacteriato to bacteria signaling. Expert Rev. AntiInfect. Therapy 5:271-276.

Uroz, S., d'Angelo-Picard, C., Carlier, A., Elasri, A., Sicot, C., Petit, A., Oger, P., Faure, D. and Dessaux, Y. 2003. Novel bacteria degrading $N$-acylhomoserine lactones and their use as quenchers of quorum-sensing-regulated functions of plantpathogenic bacteria. Microbiology (Reading, U.K.), 149: 1981-1989.

Whitehead, N. A., Barnard, A. M., Slater, H., Simpson, N. J. and Salmond, G. P. 2001. Quorum-sensing in Gram-negative bacteria. FEMS Microbiol. Rev. 25:365-404.

Yates, E. A., Philipp, B., Buckley, C., Atkinson, S., Chhabra, S. R., Sockett, R. E., Goldner, M., Dessaux, Y., Camara, M., Smith, H. and Williams, P. 2002. N-Acylhomoserine lactones undergo lactonolysis in a $\mathrm{pH}-$, temperature-, and acyl chain length-dependent manner during growth of Yersinia pseudotuberculosis and Pseudomonas aeruginosa. Infect. Immun. 70: 5635-5646. 